\title{
Spatially-resolved imaging of concentration distributions electrochemical activity distributions on corroding magnesium-based materials exposed to aqueous environments by SECM
}

Ricardo M. Soutoa,b, András Kiss ${ }^{c}$, Javier Izquierdo $^{a, b}$, Lívia Nagyc, István Bitter ${ }^{d}$, Géza Nagyc

a Department of Physical Chemistry, University of La Laguna, E-38200 La Laguna, Tenerife, Canary Islands, Spain

${ }^{b}$ Instituto Universitario de Materiales y Nanotecnologías, University of La Laguna, E-38200 La Laguna, Tenerife, Canary Islands, Spain

${ }^{c}$ Department of General and Physical Chemistry, Faculty of Sciences, University of Pécs, 7624 Pécs, Ifjúság útja 6, Hungary

${ }^{a}$ Budapest University of Technology and Economics, Budafoki u. 8, 1111 Budapest, Hungary

\begin{abstract}
The spatial resolution of $\mathrm{Mg}^{2+}$ release from magnesium and its alloys during exposure to aqueous environments has been imaged using a new, solid contact, micropipette-based magnesium-ion selective electrode employed as potentiometric tip in SECM. The detection of metal dissolution is crucial factor to detect the local microelectrodes established on the surface of the metal, and distinguish the processes related to anodic and cathodic half-cell reactions. Concentration distribution images have been obtained for the magnesium-based alloy AZ63 when galvanicallycoupled to pure iron during exposure to $1 \mathrm{mM} \mathrm{NaCl}$ solution.
\end{abstract}

Keywords: scanning electrochemical microscopy; corrosion; magnesium dissolution; ion-selective microelectrodes. 


\section{Introduction}

Elucidation of the mechanism responsible for the degradation of magnesium and its alloys in aqueous environments is required to develop efficient protection procedures for these materials to be employed in various technological applications. At present, even the identification of the species participating in the local microcells distributed on the materials during their heterogeneous corrosion remains a matter of major discussion. Particularly, the identification of the actual sites for the evolution of hydrogen gas, and the controversial initiation of metal dissolution from the nucleation of corroding pits are two major problems associated to this reaction [1-3]. In addition, contradictory experimental data are often reported on these processes, which account for the diversity of mechanisms proposed for the corrosion of magnesium [3-7]. For instance, hydrogen gas evolution has been reported both to occur exclusively at the cathodic sites [8], and at anodic and cathodic sites simultaneously, though preferentially from the anodic ones [3]. On the other hand, pitting corrosion has also been proposed to account for the initiation of metal dissolution [3,9], but confined sites have never been imaged. Though chemically different, both problems have in common a highly localized nature. Thus, there was need for spatially-resolved electrochemical information on the system, and significant advances have been accomplished since the introduction of the scanning Kelvin probe (SKP) $[10,11]$ and the scanning vibrating electrode technique (SVET) $[8,12]$ to these studies. Yet these techniques exhibit some limitations for such investigation, namely the former actually operates ex situ, whereas the later can only measure ionic flows in the adjacent electrolyte at rather big distances from the corroding surface to avoid spurious convective effects on the system produced by the mechanical vibration of the probe. More recently, potentiometric mapping of specific cations has been achieved using the scanning ion electrode technique (SIET) [13]. Ion selective micropipette electrodes with a liquid contact are employed there $[14,15]$.

The scanning electrochemical microscope (SECM) has found no use in aerated aqueous electrolytes due to the high negative potentials related to the corrosion of magnesium thus hindering amperometric operation. Then, SECM can only be operated potentiometrically using ion-selective microelectrodes as the probe. Despite some promising results, its practical application to the investigation of magnesium degradation was still severely limited by the very slow response times of the liquid contact micropipette electrodes employed [16], that only allowed to record scan lines for the most. That is, the time required to image a relevant portion of the corroding sample would be too long, and major changes in the reactivity of the sites on the metal would already occur between consecutive lines in the image grid. In order to overcome this severe limitation, we have focused on the development of new ion-selective microelectrodes for SECM operation with shorter response times and smaller internal resistances, for faster scan rates to be employed. In this work, we report the first results obtained using a new solid-contact micropipette-based design for magnesium ion selective probes. To our knowledge, imaging of the concentration distributions of $\mathrm{Mg}^{2+}$ ions during 
the corrosion of the alloy AZ63 exposed to an aqueous environment has been achieved for the first time, and the results were consistent with those obtained using the scanning vibrating electrode technique (SVET).

\section{Material and methods}

The micropipette for the microelectrode was pulled from a borosilicate glass capillary type B100-50-10 (Sutter Instruments, Novato, CA, USA), and subsequently silanized by introducing inside a few microliters of $5 \mathrm{vol} \%$ dimethyldichlorosilane solution in carbon tetrachloride. The hydrophobic layer was obtained by keeping the micropipette at $200{ }^{\circ} \mathrm{C}$ in an oven for about $30 \mathrm{~min}$. The ionophore cocktail was then filled into the micropipette by applying vacuum from the back side with an attached syringe. It was fabricated using Selectophore-grade poly(vinyl chloride) (PVC), ortho-nitrophenyl octyl ether (o-NPOE), potassium tetrakis(4-chlorophenyl)-borate (PTCB), tetrahydrofurane (THF), and tris(hydroxymethyl)aminomethane (Tris) supplied by Fluka (Buchs, Switzerland), whereas the bis- $\mathrm{N}, \mathrm{N}$-dicyclohexyl-malonamide magnesium ionophore was synthesized at the Technical University of Budapest adapting the procedure described in ref. [17]. The internal contact was provided by a $33 \mu \mathrm{m}$ diameter carbon fibre (supplied by Specialty Materials (Lowell, MA, USA) as a generous gift) inserted in the lumen of the ionophore cocktail. A copper wire was attached to the free end of the carbon fibre using silver epoxy adhesive (Amepox Microelectronics, Lodz, Poland) to provide electric contact. Loctite adhesive was used to seal the back side. Figure 1 shows a scheme of the ion selective micropipette electrode assembly and a micrograph of the obtained micropipette tip.

Experiments were performed on an epoxy resin sleeve holding $760 \mu \mathrm{m}$ diameter wires of pure iron and AZ63 magnesium alloy. The composition of the alloy was determined (in wt\%) by emission spectrometry (ICP-OES): Al 5.74, Zn 2.88, $\mathrm{Cu}<0.005$, $\mathrm{Fe}<0.005, \mathrm{Ni}<0.005, \mathrm{Si}<0.005$, Mg balance. The mount with the samples was polished with silicon carbide paper down to 4000 grit, washed thoroughly with Millipore deionised water and dried with acetone. Specimens were placed horizontally facing upwards and surrounded laterally by a small piece of PVC plastic tube creating a container for approximately $5 \mathrm{ml}$ of electrolyte solution. Tests were conducted in $1 \mathrm{mM} \mathrm{NaCl}$ solution, naturally aerated, and at ambient temperature.

The Scanning Electrochemical Microscope was manufactured by Sensolytics (Bochum, Germany). A voltage follower was introduced between the cell and the potentiometric input of the system to perform the potentiometric operation [18], and the probe was the $\mathrm{Mg}^{2+}$-ion selective microelectrode (ISME). The reference electrode was an $\mathrm{Ag} / \mathrm{AgCl} / 3 \mathrm{M} \mathrm{KCl}$. Concentration distributions over the corroding sample were determined with the ISME placed at a constant height of $100 \mu \mathrm{m}$ above the sample; scan rate: $25 \mu \mathrm{m} \mathrm{s}^{-1}$. The SVET instrumentation was manufactured by 
Applicable Electronics (New Haven, CT, USA), and operated a platinized platinum tip (20 $\mu \mathrm{m}$ dia) placed at $150 \mu \mathrm{m}$ from the sample and vibrating with an amplitude of $20 \mu \mathrm{m}$.

\section{Results and discussion}

The concentration dependence of the electrode potential for this novel $\mathrm{Mg}^{2+}$-ion selective microelectrode was calibrated using solutions of different concentration in $\mathrm{MgCl}_{2}$, keeping $1 \mathrm{mM}$ $\mathrm{NaCl}$ as the base electrolyte. Figure 2A depicts the dynamic response curve of the system, whereas the calibration curve derived from these data is plotted in Figure $2 \mathrm{~B}$. The response was linear in the concentration range of $10^{-5}$ to $10^{-1} \mathrm{M}$, and the slope was $21.7 \mathrm{mV}_{\text {decade }}{ }^{-1}$.

During galvanic corrosion, magnesium dissolves anodically to form $\mathrm{Mg}^{2+}$ ions that diffuse into the electrolyte. A heterogeneous concentration distribution of $\mathrm{Mg}^{2+}$ develops near the couple surface. 2D concentration distribution images were recorded by SECM when the $\mathrm{Mg}^{2+}-\mathrm{ISME}$ was scanned over a flat sample containing a small disk of AZ63 alloy separated ca. $5 \mathrm{~mm}$ from an iron surface disk, both inserted in an epoxy resin holder. The experiment was initiated by placing the electrodes in the small electrochemical cell, and the tip-substrate height was fixed at $100 \mu \mathrm{m}$ with the assistance of a video camera. Subsequently, the test electrolyte was admitted in the electrochemical cell. At this stage, the two metals were still electrically disconnected, thus effectively achieving their corresponding open circuit potential values in $1 \mathrm{mM} \mathrm{NaCl}$ aqueous solution. The system was allowed to stabilize for $15 \mathrm{~min}$, and then the concentration distribution map shown in Figure 3A above the AZ63 disk was obtained. The distribution of $\mathrm{Mg}^{2+}$ ions over the corroding closely matched the circular geometry of the alloy in this case. The higher concentration $(p M g=3.8)$ was found almost at the centre of the disk, and it decayed smoothly as the ISME was moved from the centre. Less than one pMg unit occurred between the highest and the lowest values in the figure.

Next, the two metals were galvanically-coupled by connecting the wires at the rear of the epoxy mount. Vigorous activation of the corrosion reaction occurred, and it was accompanied by an enhancement in the evolution of hydrogen gas from the system. An asymmetric distribution of $\mathrm{Mg}^{2+}$ ions was now measured with values apparently varying in excess of $5 \mathrm{pMg}$ units above the corroding magnesium alloy. A quantitative measurement of the total change in the ionic concentration of the metal could not be established at this time, because the potential values measured at the ISME tip when it passed above the lower third of the image were indeed more negative than those plotted in the calibration curve (cf. Figure 2B). Therefore, pMg values smaller than 1 in Figure 3B resulted from the extrapolation of the calibration line to higher concentrations of $\mathrm{Mg}^{2+}$ ions, which is rarely to hold in the system. Despite this uncertainty, it can be concluded that 
heterogeneous activation of the magnesium alloy sample occurred when the corrosion of the metal proceeded with a higher rate.

The localized nature of anodic activity on the AZ63 sample galvanically-coupled to Fe was confirmed using the scanning vibrating electrode technique (SVET). Figure 4 shows the ionic current flows in the electrolyte solution above the two metals as result of the galvanic process. Whereas the cathodic activity is observed to be evenly distributed over the iron disk (see Figure 4B), the distribution of ionic currents above the magnesium alloy is heterogeneous (cf. Figure 4A), thus indicating the simultaneous occurrence of several microanodes on the metal surface.

\section{Conclusions}

It has been described a novel assembly for the fabrication of a $\mathrm{Mg}^{2+}$-ion selective microelectrode with internal solid contact that allows its use as probe in SECM. In this work, spatially-resolved images of concentration distributions of $\mathrm{Mg}^{2+}$ ions from a corroding magnesium alloy were recorded using a rather high scan rate among those typically employed in amperometric SECM. Mg ionic species were clearly detected when the ISME passed above the magnesium disk, whereas no signal could be measured either above the surrounding epoxy resin or the iron disk.

The preliminary results reported here concerning SECM application proved their relevance towards further use of this technique in the investigation of the electrochemical activity of magnesium-based materials. Until now, SECM only allowed to follow the local depletion of dissolved oxygen in the vicinity of iron related to the cathodic activity on this metal [19]. Additionally, further miniaturization of these micropipette electrodes can be achieved quite simply using the micropipette puller and a thinner carbon fibre.

\section{Acknowledgements}

The authors are grateful to the Spanish Ministry of Science and Innovation (MICINN, Madrid, Acción Integrada No. HH2008-0011) and to the National Office for Research and Technology (NKTH, Budapest, research grant ES-25/2008 TeT) for the grant of a Collaborative Research Programme between Hungary and Spain. J.J.S., J.I. and R.M.S. are grateful for financial support by the MICINN and the European Regional Development Fund (Brussels, Belgium) under Project No. CTQ200912459. A Research Training Grant awarded to J.I. by the Spanish Ministry of Education (MECD, Madrid, Programa de Formación de Personal Investigador) is gratefully acknowledged. A.K., L.N., and G.N. acknowledge support from "Developing Competitiveness of Universities in the South Transdanubian Region (SROP-4.2.1.B-10/2/KONV-2010-0002)". 


\section{References}

1. G. Song, A, Atrens, Adv. Eng. Mater. 1 (1999) 11.

2. G. Song, A. Atrens, Adv. Eng. Mater. 5 (2003) 837.

3. G. Song, Adv. Eng. Mater. 7 (2005) 563.

4. G.G. Perrault, J. Electroanal. Chem. 51 (1974) 107.

5. P.M. Bradford, B. Case, G. Dearnaley, J.F. Turner, I.S. Woolsey, Corros. Sci. 16 (1976) 747.

6. E. Gullbransen, Electrochim. Acta 37 (1992) 1403.

7. G. Song, A. Atrens, D. StJohn, X. Wu, J. Naim, Corros. Sci. 39 (1997) 1981.

8. G. Williams, H.N. McMurray, J. Electrochem. Soc. 155 (2008) C340.

9. A.M. LaFront, W. Zhang, S. Jin, R. Tremblay, D. Dubé, E. Ghali, Electrochim. Acta 51 (2005) 489.

10. R. Hausbrand, M. Stratmann, M. Rohwerder, J. Electrochem. Soc. 155 (2008) C369.

11. G. Williams, R. Grace, Electrochim. Acta 56 (2011) 1894.

12. A.F. Galio, S.V. Lamaka, M.L. Zheludkevich, L.F.P. Dick, I.L. Müller, M.G.S. Ferreira, Surf. Coat. Technol. 204 (2010) 1479.

13. S. Lamaka, R.M. Souto, M.G.S. Ferreira. In: Microscopy: Science, Technology, Applications and Education, Vol. 3 (A. Méndez-Vilas, J. Díaz, eds.). Formatex Research Center, Badajoz (2010), p. 2162.

14. S.V. Lamaka, O.V. Karavai, A.C. Bastos, M.L. Zheludkevich, M.G.S. Ferreira, Electrochem. Commun. 10 (2008) 259.

15. O.V. Karavai, A.C. Bastos, M.L. Zheludkevich, M.G. Taryba, S.V. Lamaka, M.G.S. Ferreira, Electrochim. Acta 55 (2010) 5401.

16. J. Izquierdo, L. Nagy, I. Bitter, R.M. Souto, G. Nagy, Electrochim. Acta (2012), doi: 10.1016/j.electacta.2012.09.029.

17. K. Tóth, E. Lindner, M. Horváth, J. Jeney, E. Pungor, I. Bitter, B. Ágai, L. Töke, Electroanalysis 5 (1993) 781.

18. J. Izquierdo, L. Nagy, Á. Varga, I. Bitter, G. Nagy, R.M. Souto, Electrochim. Acta 59 (2011) 398.

19. A.M. Simões, A.C. Bastos, M.G. Ferreira, Y. González-García, S. González, R.M. Souto, Corros. Sci. 49 (2007) 726. 

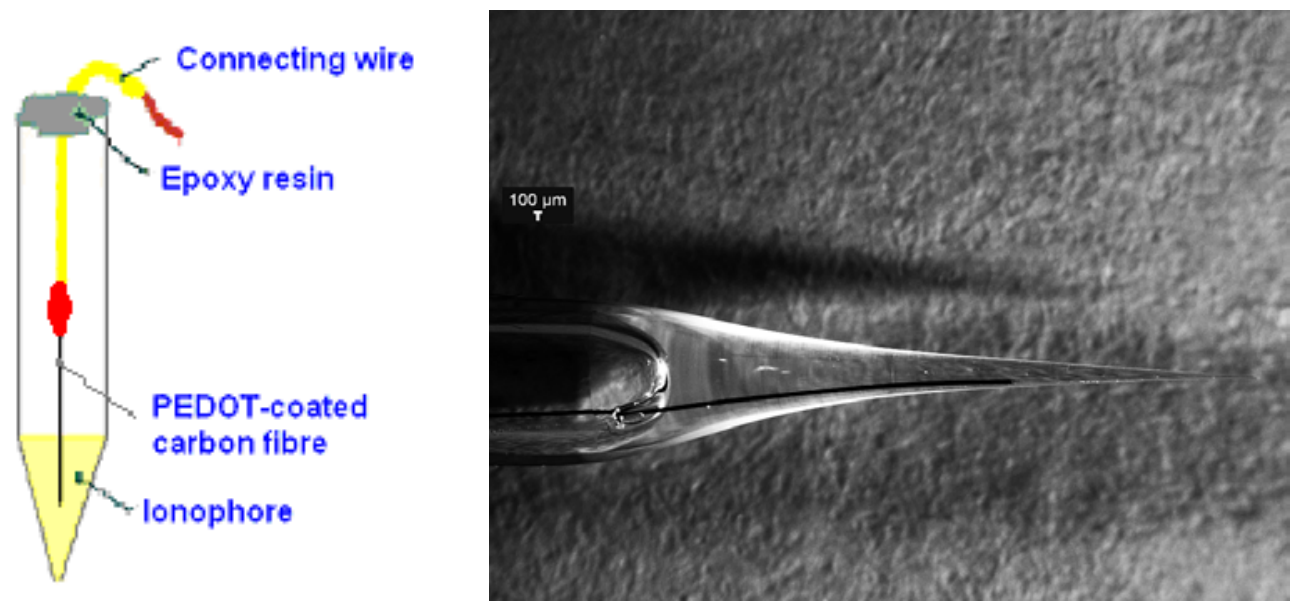

Figure 1. (A) Sketch and (B) micrograph of the micropipette electrodes fabricated for the selective detection of $\mathrm{Mg}^{2+}$ ions.
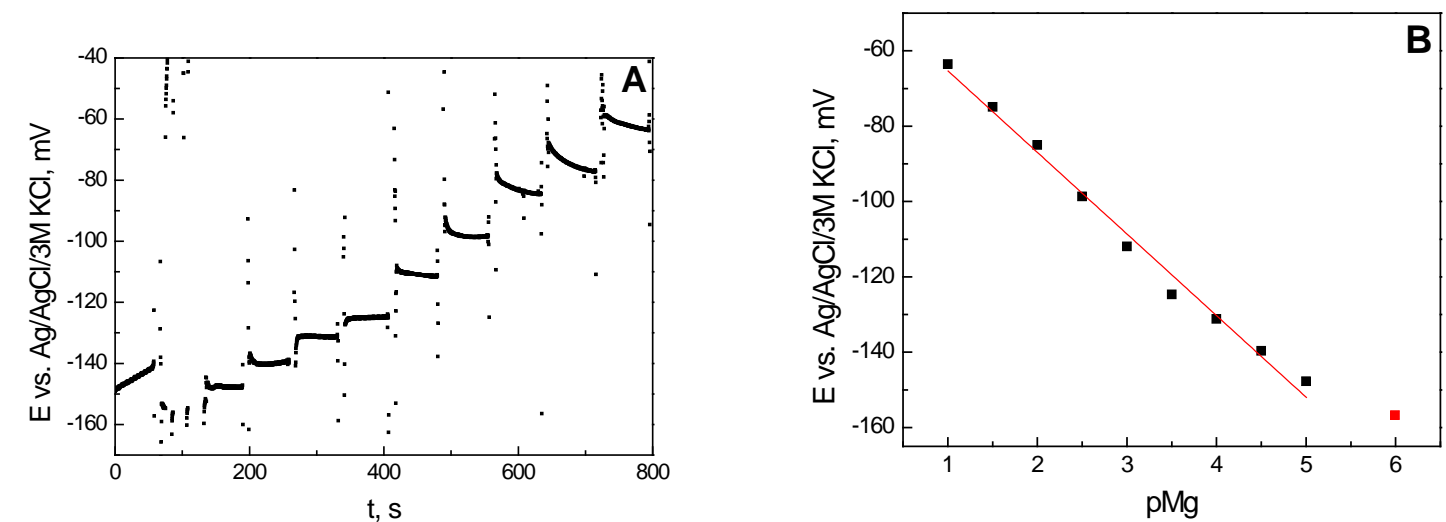

Figure 2. Calibration of the $\mathrm{Mg}^{2+}$-ion selective micropipette electrode: $(\mathrm{A})$ Dynamic response curves obtained for different $\mathrm{MgCl}_{2}$ concentrations using $10^{-3} \mathrm{M} \mathrm{NaCl}$ as background electrolyte; and (B) calibration plot.
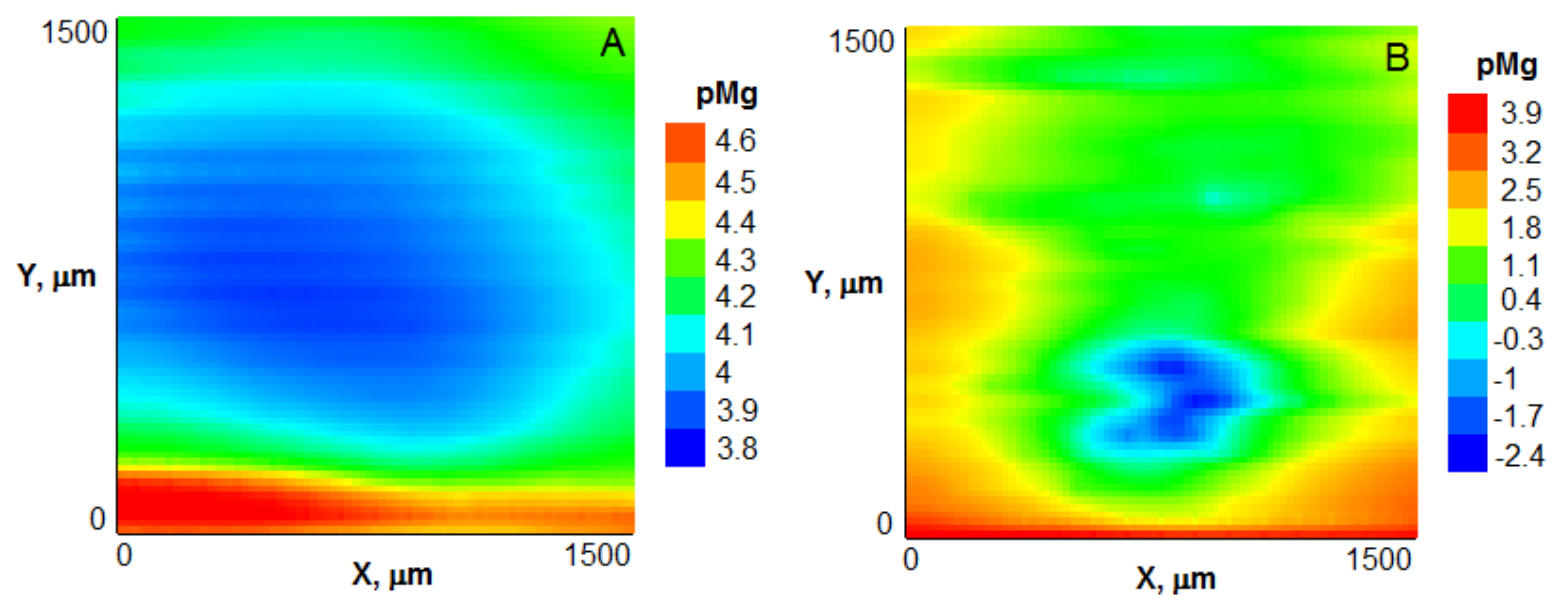

Figure 3. SECM images displaying the distribution of $\mathrm{Mg}^{2+}$ ion concentration above the $\mathrm{AZ63}$ disk in the corrosion cell containing $1 \mathrm{mM} \mathrm{NaCl}$. (A) Map recorded while the galvanic pair was disconnected, and (B) after electric contact between the two metals was produced. Tip-substrate distance: $100 \mu \mathrm{m}$; scan rate: $25 \mu \mathrm{m} \mathrm{s}^{-1}$. 

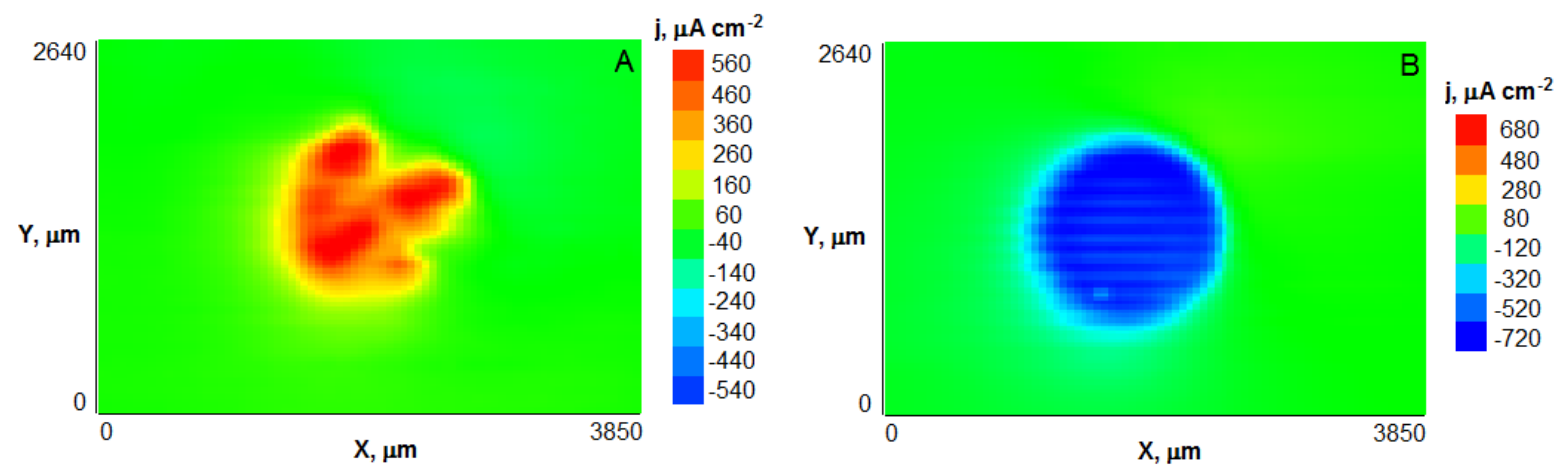

Figure 4. SVET images of the (A) AZ63 alloy and (B) Fe disks after the galvanic pair has been immersed in $1 \mathrm{mM} \mathrm{NaCl}$ for 4 hours. 